\title{
DO RODAPÉ À RODAPÉ: CRÍTICA LITERÁRIA E CONTEMPORANEIDADE
}

http://dx.doi.org/10.11606/issn.2237-1184.v0i30p93-105

Andrea Saad Hossne ${ }^{\mathrm{I}}$

RESUMO

No início do século XXI, pesquisadores ligados majoritariamente à USP, sobretudo à área de Teoria Literária e Literatura Comparada, fundada por Antonio Candido, criaram e publicaram uma revista de crítica de literatura brasileira contemporânea que, desde o título, Rodapé (referência à atividade do crítico nos rodapés de jornais), dialogava com a obra de Candido. No centenário do autor, busca-se uma reflexão acerca desse diálogo no que ele teve de problemático e nas questões que enseja para as relações entre crítica e literatura contemporânea.

\section{ABSTRACT}

In the early 21st century, a group of researchers, predominantly from USP (University of São Paulo) and its department of Literary Theory and Comparative Literature, founded by Antonio Candido, started the publication of a journal dedicated to the criticism of contemporary Brazilian literature. Starting with its title, the journal Rodapé (a reference to the critic's texts, which were customarily printed at the bottom of newspaper pages in Brazil) established a dialogue with Candido's work. In the centennial of the author's birth, this article reflects upon the problematic aspects of this dialogue and the questions it poses regarding the relationship between criticism and contemporary literature.

\section{PALAVRAS-CHAVE:}

Rodapé;

crítica literaria;

literatura contemporânea; Antonio Candido.

\section{KEYWORDS}

Rodapé;

Criticism;

Contemporary Literature;

Antonio Candido.

I Universidade de São Paulo, São Paulo, São Paulo, Brasil. 


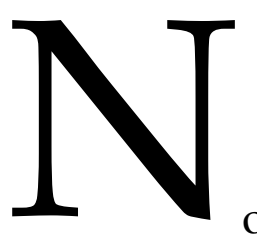

o início do presente século, mais exatamente no ano 2000, algumas pessoas, oriundas de ou próximas a dois diferentes grupos, se reuniram, um pouco a esmo, para levar adiante o projeto de criação de uma revista de crítica de literatura contemporânea brasileira.

Um dos grupos era o Cálamo, voltado, sobretudo, à criação, e dentre os que dele vieram, poetas, escritores, alguns eram também pósgraduandos em Literatura Brasileira ou em Teoria Literária na USP e docentes do ensino médio ou superior.

O outro grupo era egresso de uma comissão editorial, a da revista Magma, publicação dos pós-graduandos em Teoria Literária e Literatura Comparada da USP; um escritor e pós-graduando e uma docente, há cerca de dois anos contratada naquele mesmo departamento.

Unindo os grupos, um poeta-editor. A viabilização da revista passou justamente pelo fato de que esse poeta era à época também editor da então jovem editora Nankin, Fábio Weintraub. A Nankin, por sua vez, tem como sócio o Prof. Valentim Facioli, também da USP, hoje aposentado, da área de Literatura Brasileira. Duas de suas orientandas de doutorado, com passagem pelo ou afinidade com o Cálamo, somavam forças a esse grupo inicial: Simone Rossinetti Ruffinoni e Priscila Figueiredo, hoje docentes na mesma área. Vinculados à Teoria Literária e Literatura Comparada da USP, outros três integrantes, os doutorandos e escritores Airton Paschoa e Ana Paula Pacheco, esta também vinculada ao Cálamo, e hoje docente do mesmo departamento, e eu, a autora deste artigo, que à época, como dito, há um par de anos tinha ingressado nele como docente.

Colaboradores que não seguiram com a revista, mas participaram de suas primeiras reuniões, não tinham vínculo direto com os grupos, mas relações de afinidade e amizade com alguns de seus integrantes: Jairo Luna e Rodolfo Dantas, o primeiro também com passagem pela pós-graduação na USP.

Começo apresentando a comissão editorial e executiva dessa revista desconhecida e de curto fôlego, na sua configuração final, para apontar a dupla filiação que a preside: a universidade e a criação literária, não raro a dupla filiação no mesmo integrante. E a universidade de que se trata aqui é aquela na qual Antonio Candido era um dos elementos centrais tanto do ponto de vista da formação quanto do ponto de vista institucional, já que uma vinculação estreita, ainda que indireta, se dava com a área por ele fundada, depois transformada em Departamento.

Se existe, então, uma espécie de marca de origem, não é ela apenas a responsável pela presença forte das ideias e da atuação de Candido como 
crítico no que veio a se configurar naquilo que chamávamos, no editorial do primeiro número, publicado em 2001, o "projetinho" da revista.

Muito se discutiu acerca do nome, até que por fim, com um tanto de acanhamento, optamos por Rodapé. A homenagem era evidente, como também era evidente para nós a distância que nos separava daqueles que homenageávamos. Não os víamos como medida de nós mesmos, tal a diferença óbvia de estatura. Nem sabíamos se estávamos à altura de uma crítica militante e de intervenção como a de nossos predecessores. Movianos, porém, se não a todos, provavelmente a vários de nós, a certeza de que era necessária a disposição a fazer crítica literária de obras contemporâneas.

Se não presumíamos ser capazes de detectar entre novos autores talentos e formas maduras, ou prenúncios de futura e profícua maturidade, como o fizera Candido com Clarice Lispector, Guimarães Rosa, João Cabral etc.; se espreitávamos, com dúvidas, alguma vocação crítica, sem, no entanto, a confiança de sermos capazes de trazer à luz questões e problemas a serem enfrentados pela sensibilidade e pela reflexão, sabíamos, porém, que era necessário "desempilhar os livros", como chegamos a escrever no primeiro editorial, escavando o que chamávamos de uma "terceira margem" - expressão tão ao gosto de um dos autores, Guimarães Rosa, que constituía talvez uma espécie de paideuma subjacente a muitos do grupo - na qual os livros novos demais para a universidade daquele momento, e velhos demais para os suplementos e resenhas de jornal, encontrassem uma leitura crítica que os tirasse do limbo-prateleira em que acumulavam pó, espanado quando muito por outros escritores e leitores de grupos parecidos com o nosso, mas restritos a conversas em bares, mesas de restaurante ou balcões de lançamento de outras obras, igualmente atiradas ao limbo entre o jornal e a universidade, se não lograssem a resenha ligeira, com cara de press release, com que às vezes uma ou outra era brindada - salvo honrosas exceções, devidas mais à tenacidade de um ou outro crítico jornalista do que ao espaço dado pelos jornais.

Buscávamos, assim, o que entendíamos ser uma esfera pública (sem termos muito claro o que seria essa esfera naquele momento), onde visibilidade da produção contemporânea passasse por alguma espécie de crivo - nome, aliás, que chegamos a cogitar - e no qual esse crivo pudesse trazer à tona questões e formalizações pertinentes à matéria que nos ocupava: o Brasil que nos era contemporâneo.

Tendo Antonio Candido, Décio de Almeida Prado, Paulo Emílio Salles Gomes como parâmetros, temíamos ser tomados por megalomaníacos, por isso nossos editoriais trazem, ao lado da ideia de formação, tão presente na nossa própria, a enunciação de questões que víamos como da nossa quadra do tempo, eivada de um vocabulário da mesma esquerda que acreditávamos de alguma forma abraçar junto dos que 
homenageávamos. Falávamos em mercado, em forma-mercadoria, em alienação.

Marcava ainda o nosso "projetinho" uma sombra melancólica e meio ácida, bastante desencantada, dos anos 90 sob Itamar Franco e Fernando Henrique Cardoso. Nossa revista terminou, aliás, por coincidência, junto com a primeira eleição de Lula e a chegada do PT à presidência.

Talvez se consubstancie nesse "projetinho" chamado revista Rodapé, retomada acanhada e talvez um tanto ingênua, quem sabe por vezes equivocada na sua boa intenção, da crítica dos rodapés, uma espécie de passagem.

É à luz dessa ideia de passagem - na crítica, na literatura, na sociedade brasileira - que proponho aqui, centenário de Antonio Candido e final de um tempo1, essa aproximação entre o rodapé praticado por Antonio Candido e a precária revista que de mais de uma forma o homenageou, e de mais de uma forma, a meu ver, não pôde lhe aproveitar a lição. Talvez porque, em tempos tão difíceis, alguma homenagem que possa ser antes aprendizado do que celebração seja algo que urge.

Quando fomos convidados, no âmbito do Departamento de Teoria Literária e Literatura Comparada, a fazer parte do Seminário Antonio Candido e a Literatura, nos foi trazida a proposta de que partilhássemos com o público - nós que constituímos hoje, de um jeito ou de outro, o atual quadro docente do Departamento surgido da área por ele criada na USP - a presença de Antonio Candido, do crítico, do professor no nosso próprio trabalho docente, de críticos, de pesquisadores. Presença essa que não precisava ser sinônimo de filiação, nem mesmo de afinidade profunda, presença que poderia se fazer na diferença, na sugestão, no tangencial de um percurso próprio.

E, se no momento do convite, minha proposta era a de fazer dialogar a experiência feliz dos rodapés literários de Candido na Folha da Manhã e no Diário de São Paulo e a não tão feliz assim de uma revista da virada do século, portanto, algo que buscando alguma semelhança, se faz sobretudo diferença em relação aqueles rodapés; no dia da minha fala, o relógio dera mais uma volta com as eleições de 2018, e nessa volta, foi uma semelhança e uma busca comum o que me levou de volta ao Candido dos rodapés, no que havia ali de atitude, mais do que nas proposições acerca dos autores enfocados.

Seguir tais torções e circunvoluções não é algo simples, tem seu quê de vertigem, e foi mesmo um pouco mareada que fiz minhas ponderações.

$* * *$

\footnotetext{
1 Vale lembrar que a versão inicial desse texto foi apresentada no dia 6 de novembro de 2018, poucos dias depois do segundo turno das eleições presidenciais de 2018.
} 
Antonio Candido produziu nos rodapés, como se sabe, não apenas ensaios que tiveram depois seu destino em livros, nos quais se tornaram referência sobre uma gama diversa de autores, mas também textos acerca da própria atividade crítica e da função da crítica e do crítico.

O texto até então inédito de Candido, pertencente ao livro lançado por ocasião do centenário ${ }^{2}$, traz várias das ideias que aqueles textos nos rodapés também traziam, vistas, porém, da perspectiva privilegiada de tempo decorrido, de sínteses realizadas no que em alguns dos textos eram teses e nos seguintes antíteses - para retomar o título de um dos livros que receberam ensaios oriundos dos rodapés, como "Tese e Antítese".

Mas para a finalidade que me move - a relação entre crítica e literatura contemporânea - a síntese interessa menos que os movimentos que a ela levam, os recuos, as mudanças, as hesitações.

O "projetinho" da revista Rodapé, por sua vez, retomava a referência a tais rodapés, mas dialogava sobretudo com o crítico que superara tais recuos e mudanças, tais propostas à flor do momento, sempre enunciadas com muita clareza pelo crítico a cada passo, a cada revisão, a cada novo questionamento de perspectiva. E essa fusão talvez possa ter repercutido mal no "projetinho" da revista, porque se queria, da síntese feita, a baliza de uma crítica cujo processo ainda estava em curso, ou por se fazer (nós ainda estávamos "em curso", em processo) - e me refiro aqui apenas à voz expressa nos nossos editoriais. Não me refiro ao conjunto dos artigos de fato publicados nos três poucos números da revista. Nele, críticos maduros convivem com iniciantes, perspectivas e métodos se espraiam por vasta gama, o crítico especialista e o de jornal convivem com outros especialistas, escritores escrevem sobre outros escritores etc. A diversidade da produção é patente.

Sobre ela farei rápido comentário mais adiante, mas sempre do ponto de vista de quem fazia parte do tal "projetinho" e passadas quase duas décadas volta seu olhar para ele.

Candido, como dito acima, enunciava seus critérios, suas intenções, sua visão acerca da crítica enquanto a fazia. Assim foi, logo que iniciou em janeiro de 1943 sua colaboração na Folha da Manhã, e assim foi, mais tarde, quando completou um ano dessa atividade. E novamente o fez quando, após um intervalo de nove meses, retomou a função, em 1945, já no Diário de São Paulo.

Minha fonte, como fica evidente, é o livro organizado por Vinícius Dantas (2002) ${ }^{3}$, publicado pouco antes do terceiro número da revista Rodapé, e cujo título teve inevitável refração num debate promovido então

\footnotetext{
2 "Como e porque sou crítico". In: FONSECA, Maria Augusta e SCHWARZ, Roberto (Org.). Antonio Candido: 100 anos. São Paulo: Ed. 34, 2018.

${ }^{3}$ Trata-se, como se sabe, do conjunto composto pelos dois volumes - Textos de Intervenção e Bibliografia de Antonio Candido - organizado pelo pesquisador: DANTAS, V. (seleção, apresentação e notas). Textos de Intervenção. São Paulo: Livraria Duas cidades; Ed. 34, 2002. (Coleção Espírito Crítico).
} 
pela revista, conjuntamente com a USP e duas outras publicações, as revistas Sebastião e Cacto, também elas de curta duração. Textos de Intervenção. Mas deixo isso para mais adiante também.

Voltei aos textos de Candido e ao livro organizado por Dantas, em 2018 (a data não é mera circunstância). E ali julguei discriminar alguns tópicos que acompanham Antonio Candido ao fazer o exercício metacrítico - para o qual eu mesma não tenho grandes pendores, mas que me parece necessário neste momento.

Aos textos em que apresenta suas proposições, critérios e intenções, somo alguns outros, de mesmo teor, sobretudo o depoimento dado a Mário Neme, publicado inicialmente no jornal O Estado de São Paulo, em julho de 1943, e depois retomado em livro organizado pelo mesmo Neme, publicado em 1945, "Plataforma da nova geração".

Explico: nos textos que abrem sua colaboração nos jornais, ou fazem o balanço da atividade já realizada, Candido fala de si mesmo, sempre, porém, situando-se diante dos antecessores e de seus contemporâneos. Já no depoimento solicitado por Mário Neme, Candido tem que se haver diretamente com a noção de uma geração e de suas prováveis tarefas. No primeiro caso (os textos de abertura ou balanço), parte-se de e se chega a um jovem crítico específico, Antonio Candido, e este, para pensar sua crítica, precisa se pensar em contexto. No segundo caso, provocado por Mário Neme, parte-se de um coletivo, e de um contexto, para a ele retornar, com perspectivas de diagnóstico e prognóstico, mas para fazê-lo, é preciso passar pelo indivíduo.

Creio que não é mera obra do acaso que numa seção, intitulada "Panorâmica", já no primeiro número da revista Rodapé, figure um ensaio com o título "Geração, Gerações", de Carlos Felipe Moisés, que coloca em xeque justamente essa ideia de geração, de projeto geracional, no que, aliás, não estava sozinho. $\mathrm{O}$ que ali o poeta e crítico pensava para a produção literária não deixa de ter suas ressonâncias para outras dimensões, como a dos críticos.

Simplificando e reduzindo, na via de ida do indivíduo ao contexto e do contexto ao indivíduo dos dois conjuntos de texto do jovem Antonio Candido, publicados em jornal (os textos metacríticos e o depoimento a Neme), ideias como formação e projeto têm um sentido preciso, e implicam numa prática, a qual pressupõe indivíduo em contexto, coletividade, ou mesmo geração. Não serei eu a discorrer sobre a ideia de formação em Antonio Candido. Estudiosos argutos de sua obra vêm mostrando o que isso representa do ponto de vista da história literária; do ponto de vista de análise e interpretação da realidade brasileira e de obras que a configuram e formalizam; do ponto de vista da noção de crítica integrativa. Deixo a mãos mais competentes e a olhos mais atentos ao conjunto da obra de Candido a complexa discussão acerca da noção de formação. Nas minhas mãos e com meu olhar, restrinjo-me a essa relação entre formação e projeto, 
entre formação e possibilidade de projeto, ambos para além do restrito âmbito da individualidade, ambos compreendendo a dimensão coletiva e contextual - e assim, referindo-se não apenas à literatura, mas também ao país.

E é nessa relação entre formação e projeto, na dimensão coletiva e contextual, que nosso grupo, tão ávido de participação e intervenção, tão disponível para o desempilhar dos livros, para a busca de um estatuto qualquer de cidadania para eles na literatura, e na sociedade brasileira, não pôde, a meu ver, ir muito além da boa intenção e de ser um espaço de exercício de muitos indivíduos, igualmente imbuídos de um sentido de tarefa a cumprir, mas talvez nem sempre a mesma.

Não quero com isso menosprezar o trabalho que fizemos, nem simplesmente promover algum tipo de celebração acrítica daquele feito por Candido. Sigo uma linha que vai de Candido e dos rodapés à revista Rodapé, e que, do olhar de 2018 à revista, retorna aos rodapés, para talvez apreender ondulações - para usar um termo que o próprio Candido utiliza com frequência naqueles textos dos anos 1940 - que podem revelar liames e rupturas entre crítica e literatura contemporânea e, quem sabe, para talvez aprender alguma coisa disso tudo.

Assim, começando a retomar tudo o que anunciei que deixaria para depois, vou aos tais tópicos que julguei perceber nos textos metacríticos do jovem Candido:

1. A relação entre crítica e ética. Cito um excerto do texto de $7 / 1 / 1943$, publicado na Folha da Manhã, "Notas de Crítica Literária - Ouverture":

"Do crítico, espera-se geralmente muita coisa. Antes de mais nada, que defina o que é a crítica para ele. [...] melhor seria pedir ao crítico literário qual a sua ética - quais as imposições que se faz e quais os princípios de trabalho com os quais não transige." (DANTAS, 2002, p. 23)

Tais imposições e princípios terão, ao longo dos demais textos, o seu tanto de variação e o seu tanto de permanência, ambas se consolidando, por fim, na crítica integrativa. Assim é que, no princípio, a relação entre a obra literária e os condicionamentos sociais ocupa de tal forma o primeiro plano nos textos de 1943, que no balanço empreendido no texto de 1944, ambos ainda nos rodapés de Folha da Manhã, Candido começa a modulálos, suspeitando de um possível exagero, do qual acusará a si próprio no texto de abertura de sua colaboração, já no Diário de São Paulo, "Notas de Crítica Literária - Começando" em 20/9/1945, em que buscará abordar

“[...] o problema crítico por um ângulo oposto e de certo modo complementar [...] acentuando a magnífica especificidade graças à qual toda obra de valor é literária antes de ser sociológica ou 
política ou interessada ou desinteressada." ("Notas de crítica literária - Começando". In: DANTAS, op. cit., p. 40-1)

Isto chega ao ponto de, anos mais tarde, em 1958, às vésperas da publicação de Formação da Literatura Brasileira (1959), a propósito da crítica de Plínio Barreto, a quem ele sucedeu nos rodapés do Diário de São Paulo, e para o livro do qual redigiu o prefácio, Antonio Candido reabilitar um certo impressionismo, que ferrenhamente combatera nos textos de 1943.

Note-se, porém, que tais recuos e mudanças não são obra de arbítrio ou de casualidade, não se fazem ao sabor de caprichos, mas se ancoram no tal movimento que vai do indivíduo ao contexto e ao coletivo e vice-versa. Ao fazê-lo, permitem flagrar as tais ondulações da literatura e do próprio tempo, no feliz vocábulo empregado pelo próprio crítico. São estas ondulações e o modo como o autor as acompanha e a elas responde que fundamentarão ideias mais tarde expressas em livros como Literatura e Sociedade (1965), em textos como "Literatura e Subdesenvolvimento", "A revolução de 1930 e a cultura" (ambos de A Educação pela Noite, 1987), e darão frutos em textos de seus orientandos, como é o caso, por exemplo, quanto à discussão proposta por João Luiz Lafetá acerca dos projetos estéticos e ideológicos dos diferentes momentos do modernismo brasileiro.

O jovem crítico de 1943 declarara caber ao crítico a tarefa de

"[...] procurar tirar da obra, graças à compreensão dos seus
liames com o tempo, a inteligência deste e uma orientação para
a conduta. Interpretar a obra, numa palavra, em vista do que ela
pode ter de explicativo do seu momento. Aliás, no nosso tempo,
esta atitude se impõe." ("Notas de crítica literária - Ouverture".
(In: DANTAS, op. cit., p. 25-6)

O de 1945 analisa essa posição e explica por que é preciso superá-la naquilo em que nela se tornou exagero:

"Agindo desse modo, [eu] nada mais fazia do que conformar-me ao espírito do tempo e, por assim dizer, às necessidades da hora."

"A consequência nem sempre evitada de semelhante ponto de vista foi o aparecimento de pontos de vista políticos como critério de julgamento estético. Neste radicalismo compreensível num tempo de luta de vida e morte contra o fascismo, dentro e fora do país - os extremos foram por vezes lamentáveis. A consequência mais perigosa foi a passagem do critério mais vasto da ideologia para o sectarismo estreito dos partidos. [...] ("Notas de crítica literária - Começando". In: DANTAS, op. cit., p. 40-1)

Tais ondulações podem levar a propostas que superam posições tomadas pelo crítico, no entanto, não transigem com a ideia fundamental 
de que o crítico deva explicitar sua ética. E essa explicitação já havia sido feita no texto inicial de 1943 que se encerra da seguinte forma: "Se nem sempre é possível dizer tudo aquilo que se pensa, é sempre possível dizer apenas aquilo que se pensa. É o que farei." ("Notas de crítica literária Ouverture". In: DANTAS, op. cit., p. 30).

Creio que esse primeiro ponto, da relação entre crítica e ética, implica a relação entre crítica e política e crítica e estética, que não desenvolverei aqui e que tem sido investigada por estudiosos bem mais competentes na matéria do que eu. Mas me parece, também, que desse primeiro ponto derivam um segundo e um terceiro: o segundo é o da questão da contingência da crítica e o terceiro é o da crítica como especialidade.

Passo rapidamente pelos dois, pois creio que os três, em conjunto, implicam na relação maior entre formação e projeto, que a meu ver preside a crítica de Candido nos rodapés e se revelou problemática na retomada que dela fizemos na Rodapé.

2. Crítica e contingência: em todos os textos metacríticos, Candido deixa claro que a atividade do crítico de jornal atento à produção contemporânea é uma "atividade momentânea". ${ }^{4} \mathrm{O}$ crítico literário, segundo ele, "não visa a duração mas o seu momento". O caráter contingente e momentâneo da crítica, embora aí aproximado da atividade no jornal, não diz respeito ao veículo, mas ao olhar para a contemporaneidade. No projeto ético e político, no seu caso vinculado ao socialismo democrático, fazer crítica e lidar com o cotidiano e com o contemporâneo são parte do mesmo processo. Uma crítica que "se tornava transitória [...] esposando a palpitação da hora" ("Notas de Crítica literária - Começando". In: DANTAS, op. cit., p. 39, grifo meu).

O que leva Candido à contemporaneidade é o mesmo que o faz assumir a atividade crítica nos rodapés. Em mais de um momento, duas convergências são ressaltadas por ele: a leitura de obras do passado marcadas pela atitude empenhada, como obras da literatura portuguesa (destaca Eça de Queiroz, por exemplo) que funcionam como "bombas de retardo" ao convergirem com a "novidade sensacional" de seu tempo de primeira juventude - os romances do nordeste e seu componente social (cf. "Dos livros às pessoas". In: O Albatroz e o Chinês, 2004); e o surgimento das primeiras Faculdades de Filosofia, Sociologia, Letras ao mesmo tempo em que duas gerações iniciam e avançam na sistematização do estudo do Brasil e procedem "à análise generalizada de seus problemas" - a de 1920, a de 1930, levando ao que ele chama de uma "'brassage d'idées' nunca vista em nossa história." ("Plataforma da nova geração". In: DANTAS, op. cit., p. 239-40).

\footnotetext{
${ }^{4}$ Todas as expressões entre aspas são do próprio Antonio Candido, utilizadas mais de uma vez nos textos antes referidos. Por seu caráter reiterativo, retomo-as sem enumerar todas as fontes, de resto já enunciadas antes.
} 
3. Crítica como especialidade. Esse ponto se articula, em alguma medida, ao surgimento das mencionadas Faculdades. Se estas, somadas aos esforços das duas gerações (de 1920 e 1930) imprimem nos jovens críticos uma marca, resumida pelo autor como "uma atmosfera de crítica e de revisão, um período de violentas contradições e de enorme esforço intelectual - de onde fatalmente teríamos de sair orientados para a crítica e para a análise" (Idem), é delas também que irá emergir o especialista em literatura, e uma espécie de divisão de trabalho nos estudos literários tem início. Dirá Candido, em 1958, no já mencionado prefácio ao livro de Plínio Barreto:

"Na verdade abrangemos coisas demais sob o rótulo de crítica
[...] seria conveniente, para clareza das posições, distingui-lo, se
não na prática, ao menos em princípio, da estilística, da história,
da teoria, da erudição e da estética literária." (“Um
impressionismo válido". In: DANTAS, op. cit., p. 45-7)

Assim, o impressionismo é válido quando assegura

\begin{abstract}
“[...] a ligação entre obra e leitor, a literatura e a vida cotidiana sem prejuízo do trabalho de investigação erudita, análise estrutural, filiações genéticas, interpretação simbólica, atualmente preferidas pelo investigador da literatura [...]. Inversamente, se ela não existir, perder-se-á este ligamento vivo, e os críticos serão especialistas, no sentido que a palavra assumiu na ciência e na técnica. Ora, isto poderia ser riqueza de um lado, mas de outro, empobrecimento essencial, pois as águas ondulantes da literatura revelam muitos de seus arcanos aos barcos ligeiros, que as singram familiarmente, mais do que à perspectiva solene dos couraçados." (Idem)
\end{abstract}

Sob esse prisma, quando universidade e criação se encontraram no grupo que constituiu a revista Rodapé, há que se destacar dois aspectos: o primeiro é o de que, no momento de surgimento da revista, a universidade seguia firme na direção da formação de especialistas, para o bem e para o mal, enquanto o jornal tornara o ligeiro cada vez mais a extensão do expositor, do display pago nas grandes redes de livraria, e vinha perdendo, ele próprio, esse ligamento vivo de que fala Candido. O segundo é que a busca da "Terceira Margem", entre um e outro, não deixava ela própria de trazer consigo a marca forte da especialização universitária, na qual ideias como a de formação e de projeto, tão intrinsecamente vinculadas na geração estimulada à crítica e à análise a qual pertencia Candido, viraram, elas também, questões para especialistas, num contexto em que a ideia de projeto, a ideia de coletivo, a ideia de projeto coletivo e os sentidos mesmos 
da ideia de formação se encontravam profundamente em xeque. Acusávamos um certo anacronismo, talvez mesmo conservadorismo, nos nossos editoriais porque, ainda que não tão ingênuos assim, não tínhamos logrado vislumbrar questões de nossa época e tarefas de nosso tempo com clareza. Por isso, desempilhar os livros foi o nosso começo, e um debate intitulado "Crítica de Intervenção", ocorrido em novembro de 2002, o nosso fim.

Ali reunidos Iná Camargo Costa, José Antonio Pasta Jr, Paulo Arantes e Roberto Schwarz, com mediação de Iumna Maria Simon (todos dos quadros docentes de USP e UNICAMP), vivemos nós uma intervenção, que nos acordava tanto do desencantamento meio melancólico, meio ácido, de quem olha para o presente com olhos perdidos, sem formular claramente suas perguntas, quanto das nossas ilusões de que era de uma Terceira Margem mesmo que a nossa crítica, essencialmente universitária e especializada, se manifestava.

Hoje, estamos quase todos na USP, e aqui, nas nossas salas de aula, como o Candido da maturidade, e em nossas pesquisas e textos, alguns de nós buscamos as questões e as respostas de um tempo novamente em transição - ou em demolição. Passaram pelas páginas da revista tanto os que já eram críticos-docentes, como Fábio de Souza Andrade, Viviana Bosi, Vilma Arêas, Regina Dalcastagnè, Ítalo Moriconi, Ivone Daré Rabelo, Franklin Leopoldo e Silva, Berta Waldman, Augusto Massi, quanto os que naquele momento se experimentavam naquele e em outros espaços; não poucos deles fizeram parte direta ou indiretamente do seminário em torno do centenário de Candido, professores universitários, como Ivan Marques, Betina Bischof, Anderson Gonçalves, Edu Teruki Otsuka, Sérgio Alcides. Cada um resolvendo, para si, seus princípios e questões críticas.

Se a Rodapé pode não ter logrado, como "projetinho", "esposar a palpitação da hora", talvez tenha sido, para alguns de nós, um dos caminhos na busca por fazê-lo.

E é aqui que, na última volta do relógio, eu volto aos rodapés e dou a palavra a Candido, não de modo celebratório, mas talvez pensando se um outro tempo pode me propiciar alguma via de aprendizado para lidar com o meu próprio (cito, mais uma vez, "Plataforma da nova geração"):

[...] se você me perguntar qual 'o' dever específico da nossa geração, eu não saberei responder. Mas se me perguntar qual poderia ser, no meu modo de sentir, um rumo a seguir pela mocidade intelectual no terreno das ideias, eu lhe responderei, sem hesitar, que a nossa tarefa máxima deveria ser o combate a todas as formas de pensamento reacionário." (p. 245, grifo meu)

[...] há para todos nós um problema sério, tão sério que nos leva às vezes a procurar meio afoitamente uma 'solução': a buscar uma regra de conduta, custe o que custar. Este problema é o do medo. Do medo que nos toma a todos de estarmos sendo 
inferiores à nossa tarefa; ou de não conseguirmos fazer algo de definitivamente útil para o nosso tempo [...]. Você tem algum critério para afastar este medo? Eu não posso bem dizer que tenha, mas confesso que esse combate a todas as formas de Reação, que eu apenas sugeri, nos ajudaria muito a ficar livres dele. E a podermos dormir em paz." (p. 245; p. 249-50, grifo meu)

\section{Referências bibliográficas}

CANDIDO, Antonio. "Notas de Crítica Literária - Ouverture". Folha da Manhã. SP, 7/1/1943. In: DANTAS, Vinícius (seleção, apresentações e notas). Textos de intervenção - Antonio Candido. São Paulo: Duas cidades; Ed. 34, 2002. (Coleção Espírito Crítico).

CANDIDO, Antonio. "Notas de Crítica Literária - Começando". Diário de São Paulo, 20/9/1945. In: DANTAS, Vinícius (seleção, apresentações e notas). Textos de intervenção - Antonio Candido. São Paulo: Duas cidades; Ed. 34, 2002. (Coleção Espírito Crítico).

CANDIDO, Antonio. "Plataforma da nova geração". In: DANTAS, Vinícius (seleção, apresentações e notas). Textos de intervenção - Antonio Candido. São Paulo: Duas cidades; Ed. 34, 2002. (Coleção Espírito Crítico). CANDIDO, Antonio. “Um impressionismo válido”. In: DANTAS, Vinícius (seleção, apresentações e notas). Textos de intervenção - Antonio Candido. São Paulo: Duas cidades; Ed. 34, 2002. (Coleção Espírito Crítico).

CANDIDO, Antonio. "Dos livros às pessoas". In: O Albatroz e o Chinês. Rio de Janeiro: Ouro sobre azul, 2004.

CANDIDO, Antonio. "Como e porque sou crítico". In: FONSECA, Maria Augusta e SCHWARZ, Roberto (orgs.). Antonio Candido: 100 anos. São Paulo: Ed. 34, 2018.

Rodapé - Crítica de literatura brasileira contemporânea. n.1. São Paulo: Nankin, 2001.

Rodapé - Crítica de literatura brasileira contemporânea. n.2. São Paulo: Nankin, 2002.

Rodapé - Crítica de literatura brasileira contemporânea. n.3. São Paulo: Nankin, 2004. 
Andrea Saad Hossne é professora livre-docente do Departamento de Teoria Literária e Literatura Comparada da Faculdade de Filosofia, Letras e Ciências Humanas da Universidade de São Paulo. Foi professora e pesquisadora convidada da Université Paris 8 no ano letivo europeu de 2003-4. Escreveu o livro Madame Bovary e Lady Oracle (2000). Com Rita Olivieri Godet, organizou o livro La littérature brésilienne contemporaine: de 1970 à nos jours (2007) e, com Sandra Nitrini, organizou o livro Memória e trauma histórico: literatura e cinema (2018). Coordena, com Patrícia Trindade Nakagome (UnB), o Grupo de Pesquisa "Leitores e Leituras na Contemporaneidade" (CNPq), que publicou um e-book de mesmo título (2019). Contato: andreahossne@usp.br

ORCiD: https://orcid.org/0000-0002-7313-8073 